\title{
Nexos literarios comparativos entre Antônio da Fontoura Xavier y Rubén Darío
}

\author{
Alberto ACEREDA \\ School of International Letters and Cultures \\ Arizona State University \\ acereda@asu.edu
}

\begin{abstract}
RESUMEN
El poeta brasileño Antônio da Fontoura Xavier (1856-1922) ha sido citado como una de las fuentes del poema "Salutación al Águila" (1906) del modernista nicaragüense Rubén Darío (1867-1916). El presente artículo ofrece algunos datos que iluminan la obra de Fontoura Xavier, particularmente de su libro Opalas (1905) y su poema "A Águia Pellada" (1890), fuente mencionada por el propio Darío.
\end{abstract}

Palabras clave: Antônio da Fontoura Xavier, Rubén Darío, Modernismo, poesía brasileña

[Recibido, marzo 2011; aprobado, junio 2011]

\section{Comparative links between Antônio da Fontoura Xavier and Rubén Darío}

\begin{abstract}
The Brazilian poet Antônio da Fontoura Xavier (1856-1922) has been quoted as one of the sources for the poem "Salute to the Eagle" (1906) written by the Nicaraguan modernist poet Rubén Darío (1867-1916). This article offers some information that sheds light on Fontoura Xavier's works - particularly on his book Opalas (1905) and his poem "The Bald-Headed Eagle" (1890), a source mentioned by Darío himself.
\end{abstract}

Keywords: Antônio da Fontoura Xavier, Rubén Darío, Modernism, Brazilian poetry 


\section{Hacia Fontoura Xavier}

En la última década del siglo XIX y la primera del XX el interés de los escritores hispanoamericanos por la literatura brasileña resultó bastante escaso. El empuje del pujante Modernismo literario hispanoamericano se despreocupó en general de la sobras escritas en portugués en esos años. Leopoldo Lugones, Ricardo Jaimes Freyre, José Santos Chocano y Rubén Darío fueron excepción y, en el caso del último, y al hilo de sus labores diplomáticas nos interesa comprobar el interés dariano por la obra de varios autores brasileños, en particular por Antônio da Fontoura Xavier. ${ }^{1}$

Nacido en Cachoeira (Rio Grande do Sul) el 7 de junio de 1856, Fontoura Xavier pasó luego a estudiar en la Escuela Central de Río de Janeiro y en la Facultad de Derecho de São Paulo, si bien nunca llegó a concluir ninguno de sus estudios universitarios. Al mismo tiempo, ejerció el periodismo en parte de la prensa local como la "Gazeta de Notícias", la "Revista Ilustrada" o la "Gazetinha", publicación ésta que fundó con la ayuda de su amigo, el también poeta Artur Azevedo. Desde su juventud, Fontoura Xavier estuvo en contacto con la política y apoyó la causa republicana oponiéndose a la monarquía. Andando el tiempo, Fontoura Xavier llegó a alcanzar el puesto de diplomático de su país en los Estados Unidos y en varios países de Centroamérica y Europa. El 1 de abril de 1922, con sesenta y cinco años, murió en Lisboa ejerciendo las funciones de Embajador del Brasil en Portugal. Su vida y su obra literaria no han recibido todavía la atención crítica que merece. ${ }^{2}$ Algunos historiadores como Alfredo Bosi, por ejemplo, le dedican escasas líneas y siempre muy de pasada. Bosi coloca a Fontoura Xavier junto a Sílvio Romero, Carvalho Jr. y Valentim Magalhaes como representante de la llamada "poesía científica" y libertaria (1970: 185). Al hablar de la poesía de la década de 1870 nombra a Fontoura Xavier y su libro Opalas (1885 y 1905, en edición definitiva), colocando al poeta entre los "parnasianos" que "contribuíram com suas paráfrases de Baudelaire para encorpar o veio realista e erótico de Parnasianismo" (1970: 257).

Fuera del Brasil la crítica tampoco se ha ocupado demasiado de Fontoura Xavier. En España, apenas Ángel Crespo dedicó en su antología de la poesía brasileña unas líneas al poeta y a sus intentos de cambio poético, aunque sin

\footnotetext{
1 Para las relaciones intelectuales entre Brasil y las repúblicas hispanoamericanas a inicios del siglo XX, véase el artículo de Souza Carvalho. En cuanto al interés dariano por la literatura brasileña, el lector puede remitirse a los trabajos de Ellison, Gaibisso, Rocca y al volumen Presença do Brasil na obra de Rubén Darío. En cuanto a la recepción de la literatura hispanoamericana en el Brasil -con algunas referencias a Darío-, véase la bibliografía de Wogan.

${ }^{2}$ Los historiadores de la literatura brasileña suelen dedicar breves páginas a la vida y la obra de Fontoura Xavier y las referencias a su obra suelen ser repetitivas y superficiales, como prueba el clásico Diccionário de literatura portuguesa e brasileira. (Porto Alegre, 1967), a cargo de Celso Pedro Luft (403). En el caso de historiadores locales, véase la Historia da literatura do Rio Grande do Sul (Porto Alegre: 1956), a cargo de Ghilhermino Cesar (277-280) o las referencias en la anterior História Literária do Rio Grande do Sul (Porto Alegre, 1924), de João Pinto da Silva.
} 
seleccionar ningún poema de Fontoura Xavier. Crespo lo coloca acertadamente junto a Teófilo Dias, Carvalho Júnior y Luis Delfino, señalando que todos ellos partieron del Romanticismo cultivando una forma más equilibrada. Este general vacío bibliográfico choca con el interés que en su época tuvo el propio Rubén Darío - líder indiscutible de los modernistas hispánicos- por Fontoura Xavier. Tanto es así que el nicaragüense le dedicó una crónica en la sección póstumamente recogida como Semblanzas (1912) e incluso reconoció tener una deuda literaria con él, según detallaremos. En la época, y además del interés dariano, vale recordar el estudio introductorio que sobre el poeta escribió Aníbal Falcão ("Prefácio" a la primera edición en 1884 del libro de Fontoura Xavier: Opalas).

Como diplomático, Fontoura Xavier miró siempre a la literatura más como afición y pasatiempo que como labor profesional. La primera de sus obras lleva por título $O$ Régio Saltimbanco, texto que a modo de libelo político contra la monarquía se publicó en 1877 cuando el poeta tenía apenas veintiún años. Se trataba de un juego juvenil que satirizaba el régimen del último emperador del Brasil, Don Pedro II. O Régio Saltimbanco es precisamente el monarca, presentado ahí como arlequín y plagado de hipérboles y deformaciones de la realidad histórica. Al margen del contenido, Fontoura Xavier muestra ya un dominio de técnicas poéticas y en especial del verso alejandrino que después elevará con la publicación en 1884 de Opalas.

En su nuevo libro se halla ya una variedad de poemas de ambientes exóticos y cosmopolitas, poemas de amor y celos, muchos de ellos elaborados con la frialdad típica del parnasianismo y otros de herencia romántica con asomos a nuevos estilos. Opalas llamará años después la atención de Rubén Darío, quien por entonces manejaba y conocía algunos de los mejores poemarios de parnasianos y simbolistas franceses. Cuando Opalas ve la luz en Porto Alegre, Darío no ha publicado todavía su primer gran libro $A z u l . .$. , cuya primera edición saldrá en 1888 en Valparaíso. Andando el tiempo, en 1906, los dos poetas coincidirían en Brasil en sus respectivos cargos diplomáticos y Darío reconocerá -según mostraremos- una pequeña deuda poética con respecto a Fontoura Xavier.

\section{Opalas, de Fontoura Xavier}

Antes de entrar en el particular de la huella de Fontoura Xavier en Darío, reconocida por este mismo en cuanto a uno de sus poemas, vale la pena acercarse un poco más al volumen Opalas del brasileño para volver después a la cuestión de la fuente literaria. La primera edición de Opalas vio la luz en Porto Alegre en 1884 gracias a la labor del editor Carlo Pinto. Formaba un volumen de ciento cuarenta y cuatro páginas con un "Prólogo" de Annibal Falcão, amigo del poeta. Su prefacio parte de una perspectiva realista-positivista y constituye un ensayo del estado de la poesía brasileña del momento. Al tratar de Fontoura Xavier, Falcão encuentra una mayor preocupación por la forma y el estilo que por el contenido de los poemas, aunque no deja de entrever la tendencia social de su obra: "Ao par da sua metrificação correctissima e do seu estylo brilhante, elle 
tem ainda uma alta qualidade, a nosso ver, a mais recommendavel de quantas possue: é a tendencia, o grande ardor social que se revela nas suas poesias" (vii).

Una segunda edición del libro, la que se considera definitiva, se publicó en 1905 en Lisboa y a cargo de la Librería Editora Viúva Tavares Cardoso. ${ }^{3}$ Incluía varios poemas nuevos respecto a la anterior, así como la reproducción del "Prólogo" de 1884 de Falcão y un juicio crítico del Vizconde de S. Boaventura. Este último destacaba el interés de Fontoura Xavier por la poesía social y política, a menudo mezclado con la sátira. Boaventura traía también a colación los juicios de otros críticos de la época respecto al autor de Opalas. Así, menciona a comentaristas de la prensa local del momento como Urbano Duarte y su elogio en las páginas de $A$ Semana de Río de Janeiro (10 de enero de 1885) de la no banalidad de la obra de Fontoura Xavier. Lo mismo ocurre al mencionar a otro comentarista como Teixeira Bastos, quien en su estudio de 1895 sobre los Poetas brazileiros (Porto: Livraria Chardron) destacaba lo humano y social en el poeta de Cachoeira.

En 1928, seis años después de la muerte de Fontoura Xavier, apareció otra edición de Opalas que incluía unos "Posfacios", con opiniones de Rubén Darío (recogidas inicialmente en su crónica para Semblanzas) y otro modernista de renombre como el peruano José Santos Chocano. Este mismo autor se había encargado ya en 1914 de traducir al español los poemas de Fontoura Xavier y publicarlos en París en la editorial y librería de la viuda de Charles Bouret, edición ilustrada en una colección en la que también Darío había publicado en 1901 dos libros de la importancia de Prosas profanas y otros poemas y Peregrinaciones. Luis Alberto Sánchez ya analizó esta labor traductora de Chocano respecto a Fontoura Xavier y explicó los motivos de amistad que por razones diplomáticas unían a ambos autores.

Opalas se divide en tres secciones: "Musa livre", "Clowns" y "Ruinas", correspondientes a la visión de una musa, los saltos de un payaso y el panorama ruinoso que cierra el libro. Las composiciones aparecen fechadas cronológicamente a modo de recopilación de sus poemas y que fue ampliándose desde la primera edición de 1884 hasta la definitiva, con poemas que están fechados expresamente en un periodo de veinticinco años. Se hallan poemas de sátira y parodia ("Reliquia de Mahadura", "Roast Beef", "Segredos", "El dorado"...); poemas de amor y celos ("Estudiantina", "Pomo do mal", "Thermas de luz"...); poemas metapoéticos ("O epigramma", "Um prólogo", "Elegia"); poemas proverbiales y didácticos ("Battage", "Expansão", "Ambição"); poemas sociales y políticos ("Musa livre", "A guerra", "Ao largo" y el que aquí nos interesa más como fuente de Rubén Darío: "A Águia Pellada"...); poemas filosóficos ("Carvalho Junior", "A grande viagem", "Philosophia", "Flor da decadéncia", "Junto

\footnotetext{
${ }^{3}$ Esta es la edición que hemos utilizado, procedente de los fondos de la Biblioteca de la Universidad de Maryland, cuyo volumen tiene al inicio una dedicatoria manuscrita del propio Fontoura Xavier.
} 
de um morto"...), así como varias adaptaciones de otros poetas como Nerval, Baudelaire, Dante o Shakespeare.

Fontoura Xavier se ubica con este libro en lo que se ha venido a llamar el parnasianismo brasileño con autores como Alberto de Oliveira, Olavo Bilac, Ramiundo Correia o Vicente de Carvalho. Basta leer poemas de Fontoura Xavier como "Massas de Bronze", "Estudo anatômico", "Loura e blanca" o "A Venus de Washington" para darnos cuenta de ese tono parnasiano que -en el caso de Rubén Darío- es visible también en algunos de los medallones y poemas de $A z u l .$. (1888). Con todo, en Opalas es visible también un interés por aspectos filosóficos y meditaciones trascendentales que conectan asimismo los intereses del poeta brasileño con los del nicaragüense. El poema "Junto de um morto" es ejemplar al respecto. Dedicado a su amigo y crítico literario Alfonso Celso, este soneto indaga e interroga sobre la existencia de Dios y la del hombre mismo en el universo, aspecto que interesó siempre a Darío en su obra. En poemas como "Monólogo de um sceptico" o "Philosophia", Fontoura Xavier vuelve a cuestionar el tema de la existencia divina, con un tono de amargura que conecta con la tradición de los nocturnos de Darío y su poesía de carácter filosófico.

El soneto "A grande viagem" de Fontoura Xavier, por ejemplo, incluye toda una alegoría de la muerte en línea con el interés dariano por ese tema y en un común ambiente ligado a lo marino. Se trata del tópico de la vida como navegación (navigatio vitae), aquí con un yo poético que lo ignora todo y que llega a la reflexión del terceto final: "E vamos, vamos!, nada mais sabemos; / Senao só que nos guia n'estas ondas / A morte - o capitão que vai ao leme" (37). Las conexiones con Darío, aunque acaso como resultado de una poesía de época preocupada por estos temas, son visibles en la vertiente filosófica de la poesía del nicaragüense, como prueba el conocido poema dariano "Lo fatal" y ese desconocimiento del destino y origen del hombre. Lo mismo podría decirse en cuanto al aspecto reencarnatorio en el poema "Incognito" de Fontoura Xavier y textos como "Reencarnaciones" o "Metempsícosis" de Darío.

\section{Fontoura Xavier, fuente literaria de Rubén Darío}

Los biógrafos de Darío (Edelberto Torres o Antonio Oliver Belmás son paradigmáticos al respecto) han dado ya cuenta de la visita del nicaragüense a Brasil con motivo de la Conferencia Panamericana celebrada en Río de Janeiro en junio y julio de 1906. Designado secretario de la delegación de Nicaragua a dicha Conferencia, Darío estuvo al servicio del ministro nicaragüense Luis Felipe Corea. Será allí en Río de Janeiro donde conocerá a Antônio de Fontoura Xavier. El libro oficial de sesiones de aquella III Conferencia Panamericana incluye los nombres de Fontoura Xavier y de Darío, conformando parte de las delegaciones de Brasil y Nicaragua respectivamente. El volumen, publicado en 1907, confirma la veracidad del encuentro personal que allí tuvieron los dos poetas y ayuda a explicar el conocimiento del nicaragüense de la obra del brasileño. 
Será allí precisamente donde Darío escriba su poema "Salutación al Águila", elogiando a los Estados Unidos de América bajo su símbolo del águila. El poema, publicado unos meses después como parte del libro dariano El canto errante (1907), le valió al nicaragüense varios reproches por parte de la intelectualidad latinoamericana, dividida e irritada por entonces con el país norteamericano, como prueban los ataques a Darío por parte de voceros como Rufino Blanco Fombona y otros autores.

Los biógrafos darianos concuerdan en que Darío fue bien recibido en dicha Conferencia por las diversas delegaciones y por la intelectualidad brasileña. Elisyo de Carvalho y otros como Fontoura Xavier intercambiaron su amistad con Darío, como prueban los datos aportados por otros biógrafos como Antonio Oliver Belmás. El crítico español estudia las dos visitas de Darío a Brasil, en 1906 y 1911 y se detiene en el polémico episodio amoroso con "la Condesa de Río de Janeiro" (1960: 44-50), así como en la amistad posterior con otros escritores de lengua portuguesa como Souza Bandeira, José Verissimo, Augusto de Lima y Affranio Peixoto, además de Joaquim Nabuco, Machado de Assis y Lucio de Mendoça.

El mismo Darío recordó aquella primera amistad con Fontoura Xavier en una crónica sobre éste, recopilada años después en las Obras completas de Darío y a modo de Semblanzas (1912). Allí Darío recuerda de Fontoura Xavier: "... en el elemento oficial fue de mis amigos más cercanos" (856), y menciona al novelista Graça Aranha y al poeta Olavo Vilac. Darío recuerda que en su condición de cónsul brasileño en Nueva York, Fontoura Xavier estaba muy bien relacionado con la delegación norteamericana y que para ella escribió su poema al águila americana "que inspirara unos hexámetros míos con el mismo tema" (858). Darío, por tanto, establece como fuente inspiradora de su "Salutación al Águila" a Fontoura Xavier, lo que explica la cita que el poema dariano lleva con una frase del mismo poeta brasileño: "...May this grand Union have no end!". Darío prosigue elogiando la condición caballerosa de Fontoura Xavier y su capacidad para adaptarse a la vida norteamericana elogiando así su obra lírica tanto en portugués como en lengua inglesa. Darío elogia del brasileño no tanto su poesía política previa (que no fue precisamente del agrado del nicaragüense, a decir de éste) cuanto sus poemas de ensueño, de amor y galantería. Elogiando la estructura verbal de sus poemas, Darío lo define como "un parnasiano de la mejor ley" (861).

Especialmente interesante, a nuestro juicio, resulta la valoración general que Darío hace de Opalas en cuanto a su modernidad / contemporaneidad, palabras que muestran que la admiración de Darío por Fontoura resultaba más sincera que un mero apaño de amistad diplomática. Escribe Darío: "Su libro Opalas es un libro de elegancia y armonía, y que demuestra lo inútil y lo inconsciente de las modas literarias" (865). Darío señala que habiendo sido escrito dicho libro a lo largo de varios años y antes de la aparición de las modernísimas corrientes estéticas, Opalas "se lee hoy con igual placer que cuando apareció por la primera vez" (865). Tras ello, Darío apunta el valor permanente de la buena poesía en 
palabras que testimonian un inalterable apego dariano por la buena e imperecedera poesía: "Es que la forma y la manera -escribe Darío- valen por lo que les hace encerrar el valor creador del poeta, por lo que viene de adentro, de lo hondo del alma. En el verdadero creador prevalece la voluntad de eternidad" (865). Ese sentido de modernidad / contemporaneidad al que aludimos en nuestro somero análisis de Opalas, se armoniza aquí con la conclusión a la que llega Darío: "Por esto es que Luciano de Samosata, Píndaro, el Arcipreste de Hita, Villon, Heine y tantos otros, en el plan superior del Arte, serán por siempre contemporáneos" (865).

\section{El águila de Fontoura Xavier y el águila de Darío}

En la citada semblanza de Darío sobre Fontoura Xavier, además de reconocer la influencia del brasileño en su composición lírica "Salutación al Águila", Darío señala de Fontoura Xavier que "tiene la faz de la fuerza y la faz de la gracia. Ya veis que su Águila, por ejemplo, es soberbia" (862). Dada su difícil localización, reproduciremos aquí el texto completo del poema de Fontoura Xavier a fin de compararlo con la "Salutación al Águila" de Darío, poema más accesible y que se halla en varias ediciones contemporáneas del nicaragüense. El texto original completo del poema de Fontoura Xavier, incluido tal cual en la edición de Opalas de 1905, pero con fecha de 1890, es el siguiente (recogido en las páginas 40-42 de la edición príncipe):

\section{A Águia Pellada}

Por toda uma extensão de céo, de mar e terra,

Por toda uma extensão que vae de oceano a oceano,

E vae do Mississippi até Nova-Inglaterra,

A águia pellada enverga o vôo soberano.

Tem a cabeça branca e despida de plumas,

Mas longa na envergura a penna de remigio,

Que é o sceptro do espaço. Inda assim como algumas

Não tem c'roa real : cinge o barrete phrygio.

Sobranceira a tufões, impávida a cyclones, Ella passa affrontando ora a fúria dos mares, Ora de serra em serra o mais alto dos cones, Batendo intemerata em demanda dos ares.

E sobe, sobe, sobe. . . apoucam-se no fundo O valle, o monte, o lago, urbes e esterquilinios ...

Sobe inda mais ... mas vae quasi a roçar num mundo, Quando pára e contempla os seus vastos domínios. 
Jamais tu sob o sol, altiva águia marinha, Destendeste como ella as longas azas grandes ;

Nem vós, urubitinga, águia da serra alpina, Águia mongol ... nem tu, condor -águia dos Andes ! . .

Contam que um dia assim em que subio deveras, O raio de uma esphera abrasou-lhe a pupilla :

Ella então arrancou os raios ás espheras,

E enfeixados os tem sob a garra tranquilla.

Certo, pois, não foi ella esse abutre inhumano Que roeu n'uma rocha o ventre a Prometheu ; Nem essa que imperou sobre o mundo romano Algemada ás legiões de Cezar e Pompeu.

Grandipotente, altiva e heróica, porém nunca Carniceira e feroz águia que se não doma, Nem foi ella que outr'ora, alçando a pata adunca, Com Attila cruento abateu sobre Roma.

Águia emblema da paz, não vem também da prole D'essa outra que se ergueu sobre os bancos do Senna, Flammejou em Wagram, descahio para Arcole E ferida abateu o vôo em Santa Helena.

Ai ! ella não baixava á terra do horisonte, Como essa que, ao rugir da espessa canhonada, Tremulando adejou de Wellington na fronte, E vencida afinal passou-lhe sobre a espada.

Águia que jamais vil despojo opimo empolga, Também não vem de vós, ó negra da Teutonia, O' Jano do Danúbio, ó bifronte do Volga, O' branca, immaculada e morta da Polónia ! . . .

Jamais tu sobre a terra, altiva águia marinha, Destendeste como ella as longas azas grandes; Nem vós, águia bretan, águia da serra alpina, Águia mongol ... nem tu, condor- águia dos Andes ! . . .

Águia para abrigar um pavilhão guerreiro, $\mathrm{Ah}$ ! quem me déra ter-te, altiva e soberana, Desfraldada aos tufões sob o céo do Cruzeiro, imperando no mundo, ó águia americana! . . .

Antes de proceder a comparar este poema con el de Darío, valga señalar que el poema de Fontoura Xavier tuvo cierta fama, según prueba el hecho de que un poeta y diplomático argentino como Martín García Merou lo mencionara y aun 
tradujera al español ya en 1900 en su libro sobre la intelectualidad brasileña. Según García Merou, la primera edición de Opalas resultaba ser "uno de los libros más sugestivos de la literatura brasilera contemporánea, la revelación más clara de un talento refinado y original" (408). Como una de las más características composiciones del libro, García Merou destaca precisamente "A Águia Pellada" hasta el punto de traducirla al español, manteniendo la rima y la estructura original de Fontoura Xavier. ${ }^{4}$ En su crónica, Darío también menciona el libro y análisis de García Merou y aunque no habla de su traducción, justo es pensar que Darío también conoció dichos versos al español del argentino. Con su independencia y libertad creadora, Darío se lanzó así en 1906 a escribir su "Salutación al Águila" y no escondió nunca su deuda con Fontoura Xavier.

Una comparación de la "Salutación al Águila" de Darío con "A Águia Pellada" de Fontoura Xavier ofrece un obvio paralelismo en la mutua visión positiva de Estados Unidos, simbolizada aquí por el águila. En ambos casos se trata de versos bien provistos de una buscada rima y un ritmo solemne en elogio al ave simbólica. Son una suerte de alejandrinos en el caso de Fontoura Xavier y de hexámetros variables (combinando heptasílabos y decasílabos normalmente)

\footnotetext{
${ }^{4}$ Reproducimos aquí la traducción completa al español del poema de Fontoura Xavier vertida en 1900 por García Merou, con algunas licencias propias del crítico argentino: "Por toda una extensión de cielo, mar y tierra, / Por toda una extensión que va de océano á océano, / ufana de sus glorias, sin ambición de guerra, / El águila levanta su vuelo soberano. // Es blanca su cabeza, magnifica y pelada; / Bajo sus anchas alas lleva como un prodigio / El cetro del espacio ; y el ave sublimada / Desdeña la diadema, ciñe el bonete frigio! // Domina las borrascas y del turbión la saña. / Contempla indiferente la furia de las olas, / De pico en pico vuela audaz por la montaña / Batiendo el aire rauda y envuelta en aureolas! // Y sube, sube, sube, con júbilo profundo... / El valle, el monte, el lago, los altos promontorios, / Decrecen á sus plantas... mas al borrarse el mundo / Para, y alegre mira sus vastos territorios! // Jamás, Águila inmensa, jamás Ave marina, / Tus alas se extendieron en ámbitos más grandes, / Ni las vuestras,-oh Reina de la extensión Alpina, / Águila del Mogol, Cóndor veloz del Andes! // Cuentan que al ascender en la tormenta fiera, / Un rayo de una esfera, quemóle la pupila; / Y ella arrancó sus rayos á la remota esfera, / Y, en haz, entre su garra, consérvalos tranquila! // No fué ella, no, por cierto, aquel buitre inhumano / Que oyó de Prometeo las rudas maldiciones; / Ni la que alzaba el vuelo sobre el dosel romano, / De César y Pompeyo llevando las legiones!// Grandipotente, altiva y heroica en la pelea / Cual águila que nadie con su fiereza doma, / No fue ella la que un día paseó la roja tea / Y con Atila cruento lanzóse sobre Roma!// Tampoco ella desciende de la sangrienta prole / De esa otra que se irguiera sobre el undoso Sena, / Y que en Wagram triunfante y herida ya en Arcóle / Cayó en la roca muda, fatal de Santa Elena!// ¡Ay! Ella no pisaba sobre la tierra ardiente / Como esa, que al rugido de la batalla airada, / Cernióse majestuosa de Wellington al frente / Hasta que al fin vencida posó sobre su espada! // Águila que jamás buscara el vil despojo, / No viene de vosotras, - oh negra de Teutonia!/ ¡Oh Jano del Danubio ave del Volga rojo! / Oh blanca, inmaculada y muerta de Polonia! // Jamás, Águila inmensa, jamás Ave marina / Tus alas se extendieron en ámbitos más grandes, / Ni las vuestras, -oh Reina de la extensión Alpina! / ¡Águila del Mogol! ¡Cóndor veloz del Andes! // Para abrigar contigo mi pabellón guerrero, / ¡Águila! quién me diera tenerte soberana, / Surcando en las borrascas el cielo del Crucero, / Y emperatriz del Mundo, ¡Águila Americana! // ¿Mas quién pretender puede del ave la conquista / Ni detener su vuelo sobre el espacio azul? / Más de cien años hace que, con el arma lista, / En vano la persigue el cazador John Bull!".
} 
en Darío. En Fontoura Xavier hay paralelismos métricos con el poema "L'Albatros" de Charles Baudelaire, aunque con un contenido obviamente distinto pues el águila triunfa mientras que el ave marina baudelariana fracasa. En su poema, Fontoura Xavier destaca al águila pelada norteamericana, símbolo de aquella nación y a la que diferencia de todas las demás águilas. El águila norteamericana no es maligna como la del mito de Prometeo - al que nombra - ni como las otras águilas de imperios pasados, desde Roma a los emblemas de Atila, Napoleón y otros hechos históricos de carácter destructor. El águila norteamericana a la que saluda Fontoura Xavier es emblema de paz, águila pacífica, señorial, solemne, soberana, fuente de bien que supera las inclemencias de la naturaleza. Por vía de esta águila ascensional, superior a todas las otras águilas, Fontoura Xavier rinde así homenaje a la Unión norteamericana. Véase como en su traducción, García Merou se toma algunas licencias e introduce el personaje simbólico de John Bull, representando a Inglaterra frente a la voluntad de libertad del pueblo norteamericano. Con respecto a la comparación con Iberoamérica, Fontoura Xavier alude dos veces al cóndor, ave simbólica andina, vista aquí como "águia dos Andes", pero que Fontoura Xavier ve inferior al águila norteamericana. Darío buscará equilibrar todo esto y aludirá también al cóndor en su composición.

La "Salutación al Águila" de Darío, por su parte, fechada en Río de Janeiro en 1906, es decir dieciséis años después que el poema de Fontoura Xavier, tiene una clara voluntad diplomática de satisfacer a la delegación norteamericana asistente a la Conferencia Panamericana. Darío quiso así hacer de buen embajador y, dada su amistad con el brasileño, cabe recordar que Fontoura Xavier se lo dedicó en 1906 - y en traducción al inglés - a Elihu Root, por entonces Secretario de Estado norteamericano entre 1905 y 1909 bajo la presidencia de Theodore Roosevelt. Pese a la contradicción aparente de que Darío ya había escrito unos años antes un oda crítica "A Roosevelt", es cierto que también Darío había elogiado en otros escritos al mandatario norteamericano. Al margen de ello, en ambos poetas hay un intento de enmarcar históricamente el papel de la nueva nación norteamericana con otros países y culturas que en su día tuvieron poderío. En los dos poemas, el contraste sirve para resaltar la positiva acción de Estados Unidos en el marco de las naciones. Darío le pide al águila norteamericana que extienda sus dotes de paz y esperanza a todo el continente americano. Hay una evocación mitológica, esta vez a Júpiter, y otra literaria, a Walt Whitman. Darío invita a que el águila porte los valores positivos de trabajo, constancia, vigor y carácter, contraponiéndolos con las posibilidades de una América Latina necesitada de aprender del Norte. El elogio dariano a Estados Unidos implica en su poema, además, unión y concordia entre los dos hemisferios del continente americano, representado todo ello por una simbólica unión entre el águila y el cóndor. Darío retoma la idea de Fontoura Xavier respecto al águila como ave imperial y le añade un componente espiritual y religioso, con la expresa mención a Dios. 
Con su "Salutación al Águila", en fin, Darío homenajea a Estados Unidos pero también a Fontoura Xavier, a quien cita por vía doble en su poema, tanto en el epígrafe como en uno de los versos ("...May this grand Union have no end!"), corroborando la fuente e influencia de Fontoura Xavier, así como su mutua amistad. No se olvide que otro de los poemas de Darío, el titulado "Balada de la bella niña del Brasil", incluido en su libro Canto a la Argentina y otros poemas (1914) está dedicado significativamente a Anna Margarida, supuestamente la hija del mismo Fontoura Xavier.

La mayoría de los biógrafos y estudiosos darianos han insistido en las respuestas negativas que por parte de un sector de la intelectualidad latinoamericana del momento tuvo la publicación de "Salutación al Águila" de Darío. El venezolano Rufino Blanco Fombona fue quien de forma más vehemente atacó al nicaragüense. En una carta desde Holanda el 3 de agosto de 1907, recogida por Alberto Ghiraldo, Blanco Fombona calificó el poema de infame y afirmó: "¡Cómo no lo han lapidado a usted, querido Rubén! Le juro que lo merece. ¿Cómo? Usted, nuestra gloria, la más alta voz de la raza hispana de América, clamando por la conquista..." (141). Darío le respondió el 18 de agosto del mismo año alegando razones diplomáticas y aclarando: "Los versos fueron escritos después de conocer a Mr. Root y otros yanquis grandes y gentiles, y publicados juntos con los de un poeta del Brasil" (143). No entraremos aquí en la cuestión del debate sobre la posición de Darío ante Estados Unidos, pues ésta fue variable y a veces hasta contradictoria. En cualquier caso, el asunto del contenido político de este poema respecto al llamado imperialismo norteamericano hizo que la crítica desviara su atención y se ocupara más de esa cuestión extraliteraria que de la importante fuente dariana, expresamente reconocida por el nicaragüense, y que no es otra que el aquí estudiado poema "A Águia Pellada" de Fontoura Xavier. ${ }^{5}$

Nuestra breve aportación a las conexiones de Rubén Darío con la cultura literaria brasileña, y en particular con la obra de Antônio da Fontoura Xavier - a quien volvería a ver Darío en su posterior viaje a Brasil en 1912 - muestran la importancia de seguir estudiando todavía más a fondo el material de fuentes y nexos literarios comparativos en el eje hispano-brasileño, como confirmación de la dimensión transatlántica de la literatura iberoamericana y de los indudables lazos que unen la literatura del Brasil y la escrita en lengua española.

\footnotetext{
5 La "Salutación al Águila" ha recibido varia atención crítica por parte de diversos comentaristas y estudiosos de la obra de Darío, pero casi siempre desde la perspectiva de su posición frente al tema estadounidense. Véanse al respecto los iniciales trabajos de Marshall Nunn a finales de los años 30 pasando por los de Antonio Oliver Belmás hasta las más recientes menciones a cargo de críticos como Pablo Rocca o Jorge Eduardo Arellano.
} 


\section{Bibliografía citada}

AA.VV. (1985). Presença do Brasil na obra de Rubén Dario. Brasilia: Embajada de Nicaragua en Brasil.

AA.VV. (1907). Third International American Conference (1906). Resolutions and Documents. Rio de Janeiro: Imprensa Nacional.

ARELLANO, Jorge Eduardo (2009). "Dos poemas políticos de Rubén Darío". Revista de Temas Nicaragüenses 19: 13-26.

BOSI, Alfredo (1970). Historia concisa da literatura brasileira. São Paulo: Cultrix.

CRESPO, Ángel (1973). Antología de la poesía brasileña. Barcelona: Seix Barral.

DARÍO, Rubén. (1907) El canto errante. Madrid: M. Pérez Villavicencio.

- (1912). Semblanzas. En Obras completas (1950-1955). Madrid: Afrodisio Aguado. II/783-936.

ELLISON, Fred P. (1964). "Rubén Darío and Brazil". Hispania 47/1:24-35.

FONTOURA XAVIER, Antônio da. (1884). Opalas. Porto Alegre: Carlo Pinto \& Cía.

- (1905). Opalas. Lisboa: Livraria Editora Viúva Tavares Cardoso.

- (1928). Opalas. Rio de Janeiro: Graphica Sauer.

- (1914). Opalos; poesías escogidas y traducidas al español, por José Santos Chocano. París: Ch. Bouret.

GAIBISSO, Alicia Haydee. (1968). "Darío y las letras lusobrasileñas". Rubén Dario. Estudios reunidos en conmemoración del Centenario. La Plata: Universidad de la Plata. 494-509.

GARCÍA MEROU, Martín (1900). El Brasil intelectual. Impresiones y notas literarias. Buenos Aires: Félix Lajouane, Editor.

GHIRALDO, Alberto, ed. (1943). El archivo de Rubén Dario. Buenos Aires: Losada.

NUNN, Marshall (1937). "The americanismo of Rubén Darío". Hispania 20: 55-60.

— (1939). "Rubén Darío y los Estados Unidos". América 2: 61-64.

OLIVER BELMÁS, Antonio (1960). Este otro Rubén Darío. Barcelona: Aedos.

- (1978). "Rubén Darío y su 'Salutación al Águila', en Última vez con Rubén Darío. Madrid: Ediciones de Cultura Hispánica. 311-315.

ROCCA, Pablo (2006). "En el Brasil 'de fuego'. (Encuentros y desencuentros: Rubén Darío y Machado de Assis)". Anales de Literatura Hispanoamericana 35: 77-82.

SÁNCHEZ, Luis Alberto (1958). "Chocano, traductor. Un aspecto y un libro ignorado del gran poeta". Revista Iberoamericana 23: 113-119.

SOUZA DE CARVALHO, Ricardo (2004). "La Revista Americana (19091919) y el diálogo intelectual en Latinoamérica". Revista Iberoamericana 208-209: 665-676. 
TORRES, Edelberto (1966). La dramática vida de Rubén Dario. BarcelonaMéxico: Grijalbo.

WOGAN, Daniel S. (1948). A Literatura hispano-americana no Brasil: 18771944. Bibliografia de crítica, história literaria e traduçoes. Baton Rouge: Louisiana State University Press. 